\title{
ИСПОЛЬЗОВАНИЕ СОЦИАЛЬНЫХ СЕТЕЙ ПРАКТИКУЮЩИМИ ПСИХОЛОГАМИ ВО ВРЕМЯ ПАНДЕМИИ COVID-19¹
}

\author{
А.Е. Воробьёва \\ Институт психологии РАН \\ С.И. Скипор \\ Московский гуманитарный университет
}

\begin{abstract}
Аннотация: В статье представлены результаты пилотажного исследования использования практикующими психологами сочиальных сетей во время пандемии COVID-19.

Ключевые слова: сочиальные сети, практикующий психолог, психолог-консультант, профессиональная этика, COVID-19, ичирровые технологии
\end{abstract}

\section{SOCIAL MEDIA USE BY PRACTICING PSYCHOLOGISTS DURING THE COVID-19 PANDEMIC}

\author{
A.E. Vorobieva \\ Institute of Psychology, Russian Academy of Sciences \\ S.I. Skipor \\ Moscow University for the Humanities
}

\begin{abstract}
The article presents the results of a pilot study of the use of social networks by practicing psychologists during the COVID-19 pandemic.

Key words: social networks, practicing psychologist, counseling psychologist, professional ethics, COVID-19, digital technologies
\end{abstract}

Последние годы присутствие психолога-консультанта в пространстве социальных медиа является предметом изучения зарубежных (Afsahi, 2015; Kolmes, 2012; Kolmes, Taube, 2016; Zur, 2010) и отечественных исследователей (Воробьёва, Скипор, 2020a, 2020b; Клюева, Павлова, 2020). Известно, что социальные сети используются практикующими психологами чаще для продвижения себя как специалиста, общения с профессиональным сообществом, предоставления услуг онлайн-консультирования, а также для личного пользования без трансляции своей профессиональной роли (Kolmes, 2012).

Проведенные исследования показывают, что зачастую клиенты, потенциальные и настоящие, склонны искать психолога в социальных сетях и проверять его профиль (Afsahi, 2015; Воробьёва, Скипор, 2020а). Более того, к настоящему моменту известно, что поведение психолога и публикуемый им контент в социальной сети могут послужить предиктором доверия к нему его потенциальных

${ }^{1}$ Работа выполнена по Государственному заданию 0159-2019-0002 «Психология коллективного субъекта в изменяющихся условиях совместной жизнедеятельности». 
клиентов и коллег (Воробьёва, Скипор, 2020b). В качестве недопустимого контента для публикации психологом отмечаются негативные отзывы о коллегах, прямая реклама своих услуг, личная информация (гендер, сексуальная ориентация, подробности личной жизни), раскрытие персональных данных своих клиентов (Клюева, Павлова, 2020).

Стоит заметить, что опрошенные психологи согласны с позицией строгого следования принципам этики и безопасности в социальных сетях, они стараются формировать свою политику ведения профилей в интернете и взаимодействия с клиентами в нем, однако нечасто заранее обсуждают данные аспекты с клиентами во избежание будущих этических дилемм (Afsahi, 2015). Подобные данные о российских практикующих психологах к настоящему времени отсутствует. Интересно также, что сами психологи нередко ищут дополнительную информацию о своих клиентах, потенциальных и настоящих, в сети интернет и социальных сетях (Kolmes, Taube, 2016; Zur, 2010).

C наступлением всеобщей самоизоляции на фоне пандемии COVID-19 аспекты взаимодействия психолога и клиента в интернет-пространстве становятся принципиальными, т.к. и первый контакт, и сам процесс консультирования теперь зачастую протекают в онлайне. Вместе с тем, данных о фактическом использовании отечественными практикующими психологами социальных сетей по-прежнему недостаточно. В связи с этим цеелью нашего исследования стало изучение использования психологами-консультантами непрофессиональных социальных сетей.

Гипотезами исследования стали следующие предположения:

- психологи, добавляющие к себе «в друзья» в социальных сетях своих бывших клиентов, добавляют и настоящих клиентов;

- психологи, считающие безопасным для клиента нахождение у психолога «в друзьях» в социальных сетях, склонны принимать в друзья текущих клиентов;

- существует связь между фактом поиска психологом информации о клиенте в сети интернет и его опытом взаимодействия с неэтичными публикациями коллег в социальных медиа.

В настоящей статье представлены результаты пилотажного эмпирического исследования, проведенного в мае 2020 г. среди практикующих психологов $(\mathrm{N}=23)$, состоящих в Международной Профессиональной Ассоциации Психологов (МПАП). Опрос проводился посредством Google-форм, он был анонимным и добровольным. Материальное вознаграждение за участие в исследовании не предлагалось.

Для реализации поставленной цели нами была разработана авторская анкета, которая включала в себя вопросы о присутствии психолога в социальных сетях, его взаимодействии с клиентами и коллегами в онлайн-пространстве и мнении об этом взаимодействии, а также вопросы об особенностях интернет-консуль- 
Научные труды Московского гуманитарного университета

2020 № 5

тирования во время всеобщей самоизоляции, которые не вошли в данную публикацию. В ходе опроса респондентам было разъяснено, что под социальными сетями в данном случае подразумеваются общие, не профессиональные сайты: Facebook, VK, Одноклассники, Instagram и т.п.

Данный опрос предшествовал основному этапу исследования адаптации психологов-консультантов к онлайн-консультированию во время самоизоляции, результаты которого ожидают публикации в 2020 г. Выборку респондентов в данном опросе составили психологи, проживающие в Москве или области (73,9\%) со стажем работы до 5 лет или от 6 до 15 лет (по 43,5\%). Чуть больше половины психологов совмещают частную практику с работой в школе, больнице, психологическом центре (52,2\%), треть респондентов практикует в частном порядке (30,4\%), остальные работают в школе или больнице (17,4\%). 30,4\% опрошенных практикуют в рамках системного подхода, $26,1 \%$ в рамках интегративного или эклектичного подхода, еще 13\% указали трансактный анализ, по 8,7\% респондентов работают в когнитивно-поведенческой или психоаналитической парадигмах.

Большинство опрошенных психологов имеют профиль в социальных сетях $(91,3 \%)$ и позиционируют себя в них профессиональными психологами $(78,3 \%)$. Интересно, что значительная часть психологов продвигает свои услуги посредством своих социальных сетей $(61,9 \%)$, вместе с тем оценки эффективности этого канала продвижения разделились: $65 \%$ затруднились ответить, $30 \%$ считали этот способ рекламы своих услуг результативным, 5\% психологов подобный формат не оказался полезен. Стоит отметить, что клиенты к опрошенным психологам по-прежнему приходят главным образом посредством «сарафанного радио» $(60,9 \%)$. Также в качестве каналов привлечения клиентов респондентами были указаны профили на профессиональных сайтах и рекомендации от коллег (по 13\%).

Психологи не были единодушны в мнении о том, ищут ли их клиенты в социальных сетях: 52,2\% полагали, что да, ещё 43,5\% затруднились ответить, 4,3\% считают, что их клиенты не смотрят их профиль в социальных медиа.

Порядка $62 \%$ респондентов не добавляют в друзья в своих социальных сетях текущих и бывших клиентов, а $38 \%$ добавляют. При этом обговаривают политику взаимодействия клиент - психолог всего $52,4 \%$ опрошенных специалистов.

Также мы задали вопрос психологам о том, считают ли они безопасным для клиента его нахождение у своего психолога в друзьях в социальных сетях. Порядка $43 \%$ ответили утвердительно, около $38 \%$ затруднились с ответом, остальные (19\%) находят присутствие клиента в друзьях у своего психолога небезопасным.

На вопрос «Искали ли Вы когда-либо информацию в сети интернет о своем клиенте?» 39,1\% ответили положительно, 60,9\% отрицательно. Дополнительно нами был задан вопрос «Встречали ли Вы случаи публикации нежелательного, неэтичного материала в соцсетях со стороны своих коллег по цеху (откровенные 
фото, явное раскрытие информации о клиентах, травмирующие высказывания)?» большинство психологов ответили «нет» $(76,2 \%)$, однако $23,8 \%$ респондентов сталкивались с нарушениями этики своими коллегами в социальных медиа.

Для того, чтобы проверить выдвинутые гипотезы, мы применили процедуру точного теста Фишера, для оценки силы связи воспользовались коэффициентом Фи; все расчёты производились в программе IBM SPSS Statistics 22.0.

По результатам обработки данных выяснилось, что психологи, добавляющие в друзья своих бывших клиентов, склонны добавлять и текущих $(\varphi \risingdotseq 0,798$; $\mathrm{p}=0,001)$.

Специалисты, которые «дружат» в социальных сетях со своими настоящими клиентами, чаще находят такое взаимодействие безопасным для клиента $(\varphi \risingdotseq 0,510 ; p=0,032)$.

Также нами было обнаружено, что психологи, искавшие дополнительную информацию о своих клиентах в сети интернет, чаще замечали неэтичные публикации коллег в социальных сетях $(\varphi \risingdotseq 0,538 ; \mathrm{p}=0,018)$. Таким образом, наши гипотезы подтвердились.

Полученные нами данные свидетельствуют о том, что современные психологи используют социальные сети, в том числе для продвижения своих услуг, однако затрудняются оценить их эффективность для своей практики, по-прежнему получая основной поток клиентов по «сарафанному радио». Вероятно, использование социальных сетей для продвижения услуг осуществляется потому, что «сейчас так принято», а не потому, что это эффективно.

Интересен факт, что около половины психологов либо затруднились ответить, либо считали, что клиенты не ищут их в социальных сетях. Вместе с тем, полученные ранее данные свидетельствуют о том, что клиенты психолога склонны искать его в социальных сетях (Kolmes, Taube, 2016; Воробьёва, Скипор, 2020b).

Опрошенные психологи чаще не добавляли настоящих и бывших клиентов себе в друзья в социальных сетях. Интересно, что гипотеза о связи взаимодействия психолога с бывшими и текущими клиентами в социальных медиа, подтвердилась. Специалисты, лояльно относящиеся к нахождению у себя в друзьях бывших клиентов, в нашем исследовании также принимали запросы на дружбу от текущих клиентов.

В целом психологи-консультанты считали такое взаимодействие в социальных сетях не опасным для клиента. Между тем известно, что в некоторых случаях контент в профиле психолога может обусловить дискомфорт и ощущение пересечения определенной границы у клиента (Kolmes, Taube, 2016), а также повлиять на эмоциональную окраску отношения клиента к психологу, его профессиональным качествам (Воробьёва, Скипор, 2020b). Наша гипотеза о том, что чем безопаснее психологу кажется доступ клиента к информации с личного профиля психолога, тем более вероятно психолог будет добавлять в друзья текущих 
клиентов, подтвердилась. Примечательно, что далеко не все опрошенные психологи-консультанты обговаривают политику общения в социальных медиа с клиентами заранее, что соотносится с зарубежными исследованиями (Afsahi, 2015).

Более трети респондентов искали дополнительную информацию о своем клиенте в сети интернет, около четверти встречали неэтичный контент в профилях коллег в социальных медиа. Наше предположение о наличии связи этих двух факторов подтвердилось. Так, психологи, искавшие своих клиентов в интернете, с большей частотой встречали нежелательные публикации коллег. Это может быть объяснено фактом большей вовлеченности таких психологов в социальные медиа и интернет-пространство, что обуславливает как более частое взаимодействие с постами коллег в целом, так и более свободное отношение к этическим нормам.

Практикующие психологи активно пользуются социальными сетями, позиционируя себя в них профессионалами, однако о том, что социальные медиа стали заменой прихода клиентов по рекомендациям, говорить рано.

Психологи в целом не склонны добавлять бывших и настоящих клиентов в друзья, при этом в целом считая это безопасным для клиента. Чем менее опасным психологу видится присутствие клиента у него в профиле, тем более вероятно психолог будет добавлять клиентов к себе в друзья. Если психолог дает доступ к своему личному профилю бывшим клиентам, он склонен давать его и текущим.

Психологи, которые искали дополнительную информацию о клиенте в онлайн-источниках, чаще замечали этические ошибки своих коллег в социальных сетях.

Ограничения нашего исследования в первую очередь связаны с размером выборки, а также не стандартизированным инструментарием, который был использован при опросе.

\section{СПИСОК ЛИТЕРАТУРЫ}

Воробьёва А.Е., Скипор С.И. (2020) Психолог в социальных сетях: этика, безопасность и приемлемость// Экопсихологические исследования-6: экология детства и психология устойчивого развития, С. 443-447.

Воробьёва А.Е., Скипор С.И. (2020) Восприятие профиля психолога-практика в социальной сети Фейсбук (Facebook) потенциальными клиентами// Цифровое общество как культурно-исторический контекст развития человека: сборник научных статей/ под общ. ред. Р.В. Ершовой. - Коломна: ГСГУ. С.74-79.

Клюева Н.В., Павлова А.И. (2020) Психологические аспекты позиционирования себя как психолога-консультанта в социальных сетях // Перспективы науки и образования. № 4 (46). С. 350-359.

Afsahi A. (2015) Social Networking Dilemmas for Psychologists: Privacy, Professionalism, Boundary Issues, and Policies. Dissertation. PsyD. P.129. 
Kolmes K. (2012) Social Media in the Future of Professional Psychology // Professional Psychology: Research and Practice. 43 (6). P.606-612.

Kolmes K., Taube, D. O. (2016) Client Discovery of Psychotherapist Personal Information Online // Professional Psychology: Research and Practice. 47 (2). P.147-154.

Zur O. (2010) To Google or not to Google...our clients? When psychotherapists and other mental health care providers search their clients on the web. // Independent Practitioner. 30 (3). P. 144-148.

Воробъёва Анастасия Евгеньевна - кандидат психологических наук, старший научный сотрудник лаборатории социальной и экономической психологии Института психологии РАН. Адрес: 129366, Россия, г. Москва, ул. Ярославская, д. 13, корп. 1. Тел: +7 (495) 683-72-70; +7 (916)667-52-34. Эл. адрес: aeVorobieva@yandex.ru

Vorobieva Anastasia Evgenievna - $\mathrm{PhD}$ in Psychology, Senior researcher, Laboratory of Social and Economic Psychology, Institute of Psychology of the Russian Academy of Sciences. Postal address: 1-13, Yaroslavskaya St., Moscow, Russian Federation, 129366. Tel: +7 (495) 683-72-70; +7 (916)667-52-34. E-mail: aeVorobieva@yandex.ru

Скипор София Ильинична - выпускница факультета психологии, педагогики и социологии Московского гуманитарного университета. Адрес: 111395, Россия, г. Москва, ул. Юности, д.5. Тел: +7 (499) 374-75-95. Эл. адрес: skipor.sofia@gmail.com

Skipor Sofiia Ilynichna - graduate, Faculty of Psychology, Pedagogy and Sociology, Moscow University for the Humanities. Postal address: 5, Yunosti St., Moscow, Russian Federation, 111395. Tel.: +7 (499) 374-75-95. E-mail: skipor.sofia@gmail.com

\section{Для цитирования:}

Воробьёва А.Е., Скипор С.И. Использование социальных сетей практикующими психологами во время пандемии Covid-19 // Научные труды Московского гуманитарного университета. 2020. №5. C. 109-114. DOI: https://www.doi.org/10.17805/trudy.2020.5.12 